\title{
Computationally Efficient Semi-Analytical Model for the Calculation of the No-Load Magnetic Field in High-Speed Permanent Magnet Machines
}

\author{
Citation for published version (APA): \\ Merdzan, M. (2020). Computationally Efficient Semi-Analytical Model for the Calculation of the No-Load \\ Magnetic Field in High-Speed Permanent Magnet Machines. In 2020 15th International Conference on \\ Ecological Vehicles and Renewable Energies (EVER) [9242956] Institute of Electrical and Electronics \\ Engineers. https://doi.org/10.1109/EVER48776.2020.9242956
}

DOI:

10.1109/EVER48776.2020.9242956

Document status and date:

Published: 02/11/2020

\section{Document Version:}

Accepted manuscript including changes made at the peer-review stage

\section{Please check the document version of this publication:}

- A submitted manuscript is the version of the article upon submission and before peer-review. There can be important differences between the submitted version and the official published version of record. People interested in the research are advised to contact the author for the final version of the publication, or visit the $\mathrm{DOI}$ to the publisher's website.

- The final author version and the galley proof are versions of the publication after peer review.

- The final published version features the final layout of the paper including the volume, issue and page numbers.

Link to publication

\footnotetext{
General rights

- You may freely distribute the URL identifying the publication in the public portal. follow below link for the End User Agreement:

www.tue.nl/taverne

\section{Take down policy}

If you believe that this document breaches copyright please contact us at:

openaccess@tue.nl

providing details and we will investigate your claim.
}

Copyright and moral rights for the publications made accessible in the public portal are retained by the authors and/or other copyright owners and it is a condition of accessing publications that users recognise and abide by the legal requirements associated with these rights.

- Users may download and print one copy of any publication from the public portal for the purpose of private study or research.

- You may not further distribute the material or use it for any profit-making activity or commercial gain

If the publication is distributed under the terms of Article 25fa of the Dutch Copyright Act, indicated by the "Taverne" license above, please 


\title{
Computationally Efficient Semi-Analytical Model for the Calculation of the No-Load Magnetic Field in High-Speed Permanent Magnet Machines
}

\author{
Marko Merdzan \\ Department of Electrical Engineering \\ Eindhoven University of Technology \\ P. O. Box 513, 5600 MB Eindhoven, The Netherlands \\ Email: M.Merdzan@tue.nl
}

\begin{abstract}
High-speed slotted permanent magnet (PM) machines are characterized by high power density and high efficiency, which makes them widely used in different applications. Consequently, fast and accurate models which predict their behaviour are highly required. Eddy current effects which, due to the existence of slots, are present even at no-load conditions, impose long solving time for finite element models (FEM). As an alternative, this paper presents a harmonic model (HM) for the calculation of no-load magnetic field in high-speed slotted permanent machines. Beside having inherently shorter solving time than FEM, HM proposed in this paper brings additional reduction in the model size and solving time. This is achieved by identifying harmonic components which actually contribute to the electromagnetic field. Components which make no contribution, but are present in the generic field solution, are eliminated from the model.
\end{abstract}

Keywords-High-speed permanent magnet machines, eddy currents, slotting effect, finite element model, harmonic model, semi-analytical model, no-load magnetic field.

\section{INTRODUCTION}

No-load magnetic field in permanent magnet (PM) machines is required for the calculation of the induced electromotive force (emf), electromagnetic torque and eddy current losses due to slotting effect. A fast and accurate tool for the field calculation is the harmonic modeling (HM) method [1]. The modeling of the no-load field of slotless high-speed PM machines using the harmonic model (HM) is relatively straightforward [2], [3]. Due to the smooth stator surface, there are no other spatial harmonics introduced in the air-gap field except those present in the magnetization and therefore there are no eddy-currents in the rotor. However, in slotted machines the interaction between the magnet and the stator teeth introduces additional harmonic components. How the rotor moves and alternately passes teeth and slot openings, the magnetic field experienced in the rotating reference frame changes, causing eddy currents in the rotor.

To model eddy currents using the HM, the frequency at which the electromagnetic field varies in the domain with eddy currents needs to be known. If magnetic field originates from the stator currents, the rate of change of the field is determined by the frequency of the currents [4]. If the excitation is the rotor magnet, the rate of change of the total field is proportional to the product of the rotor mechanical speed and the number of slots. In the latter case, however, the frequency associated to individual spatial harmonic components in the HM, required for the implementation, is not known in advance. This paper demonstrates a procedure to determine this frequency. Initially, a magnetostatic model of a benchmark machine is solved. Using this solution for 2 different rotor positions, the required frequency for different spatial harmonic components is obtained. Then, the full HM with included eddy currents is implemented. To make the model smaller in size, computationally more efficient and stable, the magnetostatic model is also used to predict and eliminate harmonics component which do not contribute to the field.

The benchmark machine, used for the verification of the model is shown in Figure 1, while its parameters are listed in Table I. It has a fully cylindrical magnet on the rotor, magnetized diametrically and contained in a metallic retaining sleeve. Although it utilizes concentrated coils, this topology is not characterized by a rich spatial harmonic content of the armature electromagnetic field in the air-gap [5], which allows it to be used for the high-speed operation [6], [7]. To decrease the complexity of the model, it is assumed that slot openings and slots have the same width equal 


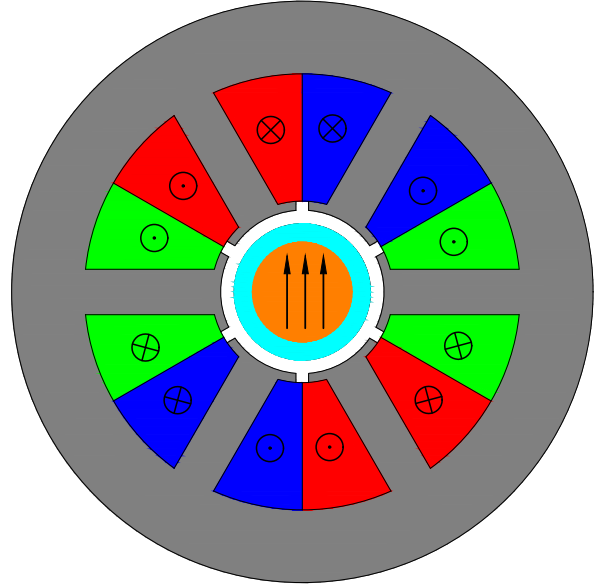

Fig. 1. Benchmark high-speed machine used for the verification of the developed model.

TABLE I. PARAMETERS OF THE BENCHMARK HIGH-SPEED MACHINE.

\begin{tabular}{|l|c|c|c|}
\hline Parameter & Symbol & Value & Unit \\
\hline Fundamental frequency & $f_{0}$ & 4 & $\mathrm{kHz}$ \\
Relative permeability of the magnet & $\mu_{\mathrm{rm}}$ & 1.035 & - \\
Electric conductivity of the magnet & $\sigma_{\mathrm{m}}$ & $6.25 \cdot 10^{5}$ & $\mathrm{~S} / \mathrm{m}$ \\
Remanent flux density of the magnet & $B_{\mathrm{rem}}$ & 1.19 & $\mathrm{~T}$ \\
Relative permeability of the sleeve & $\mu_{\mathrm{rs}}$ & 1 & - \\
Electric conductivity of the sleeve & $\sigma_{\mathrm{s}}$ & $8.33 \cdot 10^{5}$ & $\mathrm{~S} / \mathrm{m}$ \\
Number of turns per phase & $N$ & 68 & - \\
Slot opening width & $\mathrm{s}_{\mathrm{in}}$ & 10 & degree \\
Axial length & $l_{\mathrm{s}}$ & 25 & $\mathrm{~mm}$ \\
Magnet radius & $r_{\mathrm{m}}$ & 5.5 & $\mathrm{~mm}$ \\
Sleeve outer radius & $r_{\mathrm{sl}}$ & 7.5 & $\mathrm{~mm}$ \\
Stator inner radius & $r_{\mathrm{si}}$ & 9 & $\mathrm{~mm}$ \\
Slot outer radius & $r_{\mathrm{sb}}$ & 24 & $\mathrm{~mm}$ \\
Yoke outer radius & $r_{\mathrm{yo}}$ & 32 & $\mathrm{~mm}$ \\
\hline
\end{tabular}

to $s_{\text {in }}$ given in Table I. Therefore, each slot and the corresponding slot opening are merged into a single slot region. This is commonly used assumption made in the HM, and typically does not introduce a significant error in the calculation of the magnetic field in the air-gap and the rotor [1]. Furthermore, the stator iron is considered to be infinitely permeable and the field in iron is not modeled. The magnetic field is assumed to be 2-dimensional, described in polar coordinates.

\section{Magnetostatic MODEL}

The harmonic modeling method is based on the analytical solution of the governing equation in terms of the magnetic vector potential, which is derived from Maxwell's equations. For the no-load magnetostatic situation (no imposed current density or eddy current density) and considered magnetization pattern, the governing equation is given by [8]

$$
\nabla^{2} A_{z}=0 .
$$

The single existing component of the vector potential, the axial one, is indicated by $A_{z}[\mathrm{~Wb} / \mathrm{m}]$. Equation (1) is valid in all regions of the machine where the field is calculated. Its general solution valid in the magnet region can be written using the complex Fourier series as

$$
A_{z}^{\mathrm{m}}\left(r, \theta_{\mathrm{r}}\right)=\sum_{k_{\mathrm{p}}=-\infty}^{\infty} \bar{C}_{\mathrm{m}}\left(\frac{r}{r_{\mathrm{m}}}\right)^{\left|k_{\mathrm{p}}\right|} e^{j k_{\mathrm{p}} \theta_{\mathrm{r}}} .
$$

In the retaining sleeve the general solution has the following form

$$
A_{z}^{\mathrm{s}}\left(r, \theta_{\mathrm{r}}\right)=\sum_{k_{\mathrm{p}}=-\infty}^{\infty}\left(\bar{C}_{\mathrm{s}}\left(\frac{r}{r_{\mathrm{sl}}}\right)^{k_{\mathrm{p}}}+\bar{D}_{\mathrm{s}}\left(\frac{r}{r_{\mathrm{sl}}}\right)^{-k_{\mathrm{p}}}\right) e^{j k_{\mathrm{p}} \theta_{\mathrm{r}}},
$$

and equivalently in the air-gap

$$
A_{z}^{\mathrm{g}}\left(r, \theta_{\mathrm{r}}\right)=\sum_{k_{\mathrm{p}}=-\infty}^{\infty}\left(\bar{C}_{\mathrm{g}}\left(\frac{r}{r_{\mathrm{si}}}\right)^{k_{\mathrm{p}}}+\bar{D}_{\mathrm{g}}\left(\frac{r}{r_{\mathrm{si}}}\right)^{-k_{\mathrm{p}}}\right) e^{j k_{\mathrm{p}} \theta_{\mathrm{r}}} .
$$

In (2)-(4), $r$ and $\theta_{\mathrm{r}}$ are the radial coordinate and the circumferential coordinate in the rotor reference frame, respectively, while radii used for the normalization of the solution are given in Table I. Terms $\bar{C}_{\mathrm{m}}, \bar{C}_{\mathrm{s}}, \bar{D}_{\mathrm{s}}$, $\bar{C}_{\mathrm{g}}, \bar{D}_{\mathrm{g}}$ are unknown complex constants. If $N_{\mathrm{p}}$ is the maximum value that $k_{\mathrm{p}}$ takes during the implementation of the model, expressions (2)-(4) contain $10 N_{\mathrm{p}}$ constants in total. Expressions (3) and (4) have identical form, and the retaining sleeve and the air-gap could be modeled as a single region in the magnetostatic model, simplifying it and decreasing its size. However, these regions have to be modeled separately in the model with eddy currents. The model size reduction, shown in the following section, is illustrated using the magnetostatic model. However, it is equally valid for the model with eddy currents. Therefore, the sleeve and the air-gap are modeled as separate regions even in the magnetostatic model, to clearly demonstrate the benefits of the reduction of the model size, which are also utilized in the model including eddy currents.

The general solution of (1), valid in each slot denoted by index $i$, is given by the real Fourier series as

$$
\begin{aligned}
A_{z}^{\mathrm{u} i}\left(r, \theta_{\mathrm{sl}}^{i}\right)=\sum_{k_{\mathrm{np}}=1}^{\infty} & \left(C_{\mathrm{u}}^{i}\left(\frac{r}{r_{\mathrm{sb}}}\right)^{\frac{k_{\mathrm{np}} \pi}{\mathrm{sin}_{\mathrm{in}}}}+D_{\mathrm{u}}^{i}\left(\frac{r}{r_{\mathrm{sb}}}\right)^{-\frac{k_{\mathrm{np}} \pi}{\mathrm{sin}_{\mathrm{in}}}}\right) \\
& \cdot \cos \left(\frac{k_{\mathrm{np}} \pi}{\mathrm{s}_{\mathrm{in}}} \theta_{\mathrm{sl}}^{i}\right) .
\end{aligned}
$$

Terms $C_{\mathrm{u}}^{i}$ and $D_{\mathrm{u}}^{i}$ are unknown constants in each slot, while $\theta_{\mathrm{sl}}^{i}$ is the circumferential coordinate in the local slot reference frame, fixed to the edge of the slot. The reference frame positioned in this way gives only the cosine component for the vector potential in slots [9]. 
If $N_{\mathrm{np}}$ is the maximum value that $k_{\mathrm{np}}$ takes during the implementation of the model, and $N_{\mathrm{s}}$ is the number of slots, expression (5) contains $2 N_{\mathrm{s}} N_{\mathrm{np}}$ constants.

By using the definition of the magnetic vector potential [10]

$$
\vec{B}=\nabla \times \vec{A},
$$

and the constitutive relation for the permanent magnet material

$$
\vec{B}=\mu_{0} \mu_{\mathrm{r}} \vec{H}+\vec{B}_{\mathrm{rem}},
$$

the radial magnetic flux density $B_{r}[\mathrm{~T}]$ and the circumferential magnetic field strength $H_{\theta}[\mathrm{A} / \mathrm{m}]$ can be expressed in each region, respectively, as

$$
B_{r}(r, \theta)=\frac{1}{r} \frac{\partial A_{z}(r, \theta)}{\partial \theta},
$$

and

$$
H_{\theta}(r, \theta)=-\frac{1}{\mu}\left(\frac{\partial A_{z}(r, \theta)}{\partial r}+B_{\theta \mathrm{rem}}(\theta)\right) .
$$

In (9) $B_{\theta \mathrm{rem}}[\mathrm{T}]$ is the circumferential component of the remanent flux density. $B_{\theta \text { rem }}$ in (9) models the influence of the magnetization, despite it not being explicitly present in (1). By utilizing (8) and (9), a set of boundary condition equations can be defined, respecting the continuity of $B_{r}$ and $H_{\theta}$ at radii which separate different regions. At $r_{\mathrm{m}}, r_{\mathrm{sl}}$ and $r_{\mathrm{sb}}$, boundary conditions are valid for each individual spatial harmonic component, since a single fundamental period is used. At radius $r_{\mathrm{si}}$, which separates the air-gap (with the fundamental spatial period of $2 \pi$ ) and slots (the fundamental spatial period $2 \mathrm{~s}_{\text {in }}$ ), the situation is different.

Circumferential components of the magnetic field strength in the air-gap $\left(H_{\theta}^{\mathrm{g}}\right)$ and each slot $\left(H_{\theta}^{\mathrm{u} i}\right)$ are equal over the boundary between the air-gap and the corresponding slot. At the interface with infinitely permeable teeth, $H_{\theta}^{\mathrm{g}}$ is zero. If the expression for the calculation of complex Fourier coefficients in the air-gap is applied on this boundary condition, an equation relating peak values of $H_{\theta}^{\mathrm{g}}$ and $H_{\theta}^{\mathrm{u} i}$ can be written for each value of $k_{\mathrm{p}}$ as

$$
\hat{\bar{H}}_{\theta}^{\mathrm{g}}\left(r=r_{\mathrm{si}}, k_{\mathrm{p}}\right)=\sum_{i=1}^{N_{\mathrm{s}}} \sum_{k_{\mathrm{np}}=1}^{\infty} \hat{H}_{\theta}^{\mathrm{u} i}\left(r=r_{\mathrm{si}}\right) \chi^{i}\left(k_{\mathrm{p}}, k_{\mathrm{np}}\right) .
$$

Function $\chi^{i}$ is evaluated as

$$
\chi^{i}\left(k_{\mathrm{p}}, k_{\mathrm{np}}\right)=\frac{1}{2 \pi} \int_{\delta^{i}}^{\delta^{i}+\mathrm{s}_{\mathrm{in}}} \cos \left(\frac{k_{\mathrm{np}} \pi}{\mathrm{s}_{\mathrm{in}}} \theta_{\mathrm{sl}}\right) e^{-j k_{\mathrm{p}} \theta_{\mathrm{r}}} \mathrm{d} \theta_{\mathrm{r}},
$$

where $\delta^{i}$ is the position of the origin of the local slot reference frame expressed in the rotor reference frame.

Radial components of the magnetic flux density in each slot $\left(B_{\mathrm{r}}^{\mathrm{u} i}\right)$ and the air-gap $\left(B_{\mathrm{r}}^{\mathrm{g}}\right)$ are equal over boundaries between each slot and the air-gap. If the expression for the calculation of the Fourier coefficients of sine terms in slots is applied on these boundary conditions, for each value of $k_{\mathrm{np}}$ in each slot an equation relating peak values of $B_{\mathrm{r}}^{\mathrm{u} i}$ and $B_{\mathrm{r}}^{\mathrm{g}}$ can be written as

$$
\hat{B}_{r}^{\mathrm{u} i}\left(r=r_{\mathrm{si}}, k_{\mathrm{np}}\right)=\sum_{k_{\mathrm{p}}=-\infty}^{\infty} \hat{\bar{B}}_{r}^{\mathrm{g}}\left(r=r_{\mathrm{si}}\right) \xi^{i}\left(k_{\mathrm{np}}, k_{\mathrm{p}}\right),
$$

where $\xi^{i}$ is calculated as

$$
\xi^{i}\left(k_{\mathrm{np}}, k_{\mathrm{p}}\right)=\frac{2}{\mathrm{~s}_{\mathrm{in}}} \int_{0}^{\mathrm{s}_{\mathrm{in}}} e^{j k_{\mathrm{p}} \theta_{\mathrm{r}}} \sin \left(\frac{k_{\mathrm{np}} \pi}{\mathrm{s}_{\mathrm{in}}} \theta_{\mathrm{sl}}^{i}\right) \mathrm{d} \theta_{\mathrm{sl}}^{i} .
$$

Expressions (11) and (13) are evaluated using the following relation between $\theta_{\mathrm{r}}, \theta_{\mathrm{sl}}^{i}$ and $\delta^{i}$

$$
\theta_{\mathrm{sl}}^{i}=\theta_{\mathrm{r}}-\delta^{i} .
$$

The developed model is implemented for the benchmark machine by setting $N_{\text {np }}$ at 5 . To get the lowest possible calculation error, $N_{\mathrm{p}}$ is chosen according to [1], as

$$
N_{\mathrm{p}}=N_{\mathrm{np}} \frac{\pi}{\mathrm{s}_{\mathrm{in}}},
$$

which sets $N_{\mathrm{p}}$ at 90 . This results with the model containing 960 equations. The model is implemented for the position in which the d-axis of the rotor is aligned with one slot edge, with the calculation time of 0.25 seconds. The validation is done using 2D finite element model (FEM), and results are shown in Figures 2 and 3 , where the radial and circumferential components of the air-gap flux density are shown. A good agreement is achieved, with the discrepancy between RMS values of the flux density components corresponding to the HM and FEM of $0.07 \%$ and $0.72 \%$ for the radial and the circumferential component, respectively.

\section{MODEL SIZE REDUCTION}

By analyzing previously derived magnetostatic field solution, it is possible to decrease the calculation time and the size of the model by reducing the number of used equations, without losing accuracy. If harmonic peak values of any field quantity in the air-gap region are observed, at an arbitrary radius, it can be seen that certain harmonic components have value zero. By removing these components from the model, the number of equations can be significantly reduced. 


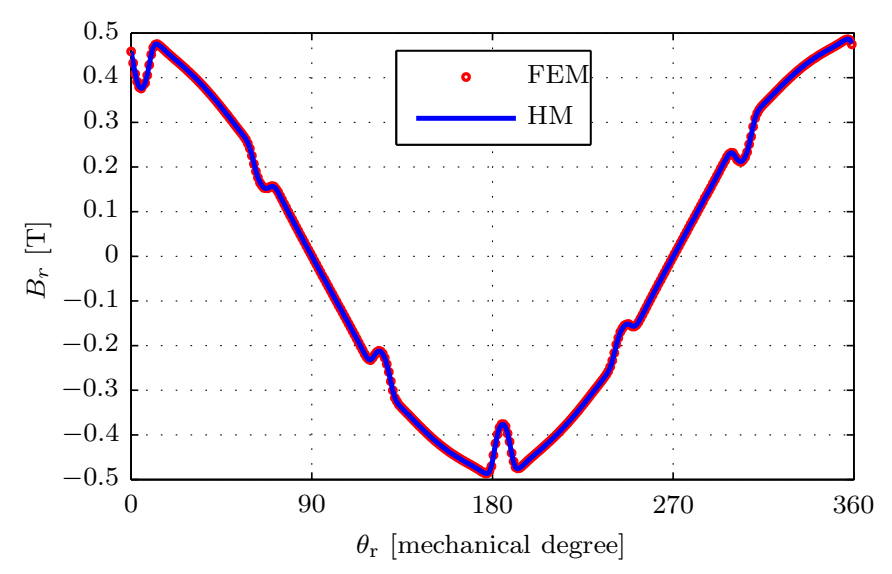

Fig. 2. Radial component of the magnetic flux density in the air-gap, at radius $8.5 \mathrm{~mm}$.

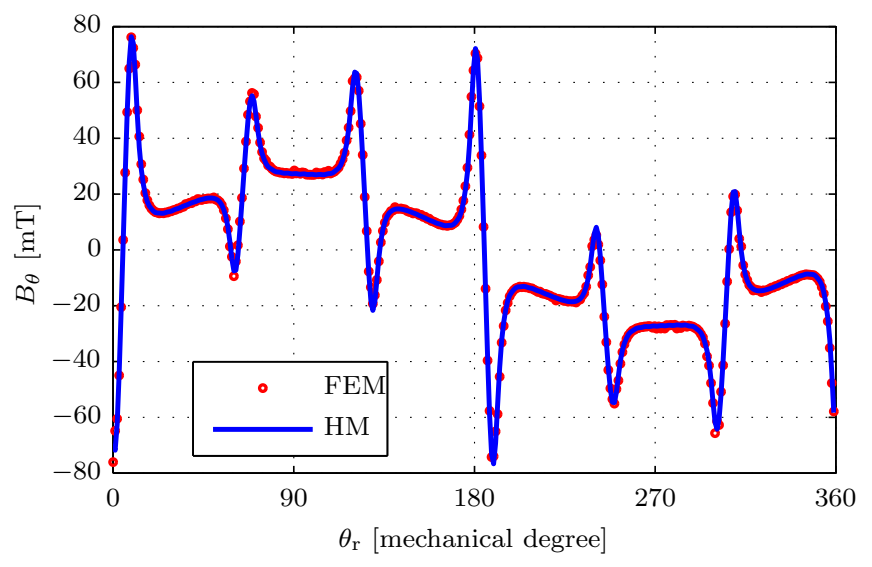

Fig. 3. Circumferential component of the magnetic flux density in the air-gap, at radius $8.5 \mathrm{~mm}$.

Table II shows index $k_{\mathrm{p}}$ for first 9 harmonic components having non-zero values in the permanent magnet field model for the benchmark machine. Any pair of components with the same absolute value of $k_{\mathrm{p}}$ from Table II contributes to a single spatial harmonic of order $k_{\mathrm{pm}}$. Based on values shown in Table II it can be concluded that machines having a magnet with diametrical magnetization, beside the fundamental spatial harmonic, generate in periodic regions spatial harmonics of following orders

$$
k_{\mathrm{pm}}=p N_{\mathrm{s}} \pm 1
$$

where $p$ is a positive integer, and $N_{\mathrm{s}}$ is the number of slots. A formulation equivalent to (16) is also given in [11]. The magnetostatic model is implemented once

TABLE II. INDEX $k_{\mathrm{P}}$ OF NON-ZERO HARMONIC COMPONENTS FOR THE BENCHMARK MACHINE.

\begin{tabular}{|l|l|l|l|l|l|l|l|l|l|}
$k_{\mathrm{p}}$ & \pm 1 & \pm 5 & \pm 7 & \pm 11 & \pm 13 & \pm 17 & \pm 19 & \pm 23 & \pm 25 \\
\hline
\end{tabular}

more, considering only components which actually contribute to the field in periodic regions, for which holds

$$
k_{\mathrm{p}}= \pm k_{\mathrm{pm}}
$$

The maximum value of $k_{\mathrm{pm}}$ corresponds to the value $N_{\mathrm{p}}$ used in the full model. The number of harmonics used in each slot, $N_{\text {np }}$, is also the same as in the full model. The reduction in the number of equations leads to a significant decrease in the calculation time and the size of the model. Namely, the model of the benchmark machine reduces to 370 equations, which is approximately 2.6 times lower than in the full model. Consequently, the total number of elements in the system matrix (that has to be inverted to obtain the unknown constants) decreases more than 6.5 times. Additionally, the calculation time reduces to $0.15 \mathrm{~s}$. The model with included eddy currents, which will follow, is therefore implemented only with the reduced number of equations.

\section{TIME DEPENDENCY IN THE ROTATING REFERENCE FRAME}

The stator geometry is periodic in the circumferential direction, with the fundamental spatial period equal to one slot pitch. Therefore, the electromagnetic field expressed in the rotor reference frame is the same in any 2 instants of time which differ for the period required for the rotor to change its position for one slot pitch. Therefore, the frequency of variations of the electromagnetic field seen by the rotor is given by

$$
f_{\text {rot }}=N_{\mathrm{s}} f_{0},
$$

where $f_{0}[\mathrm{~Hz}]$ is the frequency corresponding to the rotor mechanical speed. However, this is valid for the total field, which is modeled as a summation of different spatial harmonics. To properly include time dependency in the electromagnetic field model, frequencies associated to time variations of each spatial harmonic component have to be known.

Expressions (2)-(4) can be more complectly represented using the generic expression

$$
A_{z}\left(r, \theta_{\mathrm{r}}\right)=\sum_{k_{\mathrm{p}}=-\infty}^{\infty} \hat{\bar{A}}_{z}\left(r, k_{\mathrm{p}}\right) e^{j k_{\mathrm{p}} \theta_{\mathrm{r}}}
$$

where the solution in the radial direction $\hat{\bar{A}}_{z}$ contains unknown constants. If any of the constants is evaluated for different rotor positions, it can be seen that its modulus does not change with the position (and consequently with time). Since only arguments of complex constants change with the rotor position (and consequently with 
time), any constant can, using a generic complex variable $\bar{C}$, be represented as

$$
\bar{C}\left(k_{\mathrm{p}}\right)=\bar{C}^{0}\left(k_{\mathrm{p}}\right) e^{j \beta\left(k_{\mathrm{p}}, t\right)},
$$

where $\bar{C}^{0}$ is a value of a complex constant at arbitrary rotor position (arbitrary instant of time), while $\beta$ represents time (position) dependent variable which describes the change of the argument of $\bar{C}$ with the position (and consequently with time). If $\bar{C}^{\theta_{0}}$ represents the value of $\bar{C}$ at the initial rotor position $\theta_{0}$ (for time instant $t=0$ ), variable $\beta$ can be represented as

$$
\beta\left(k_{\mathrm{p}}, t\right)=l_{\mathrm{p}}\left(k_{\mathrm{p}}\right) \omega_{0} t
$$

where $l_{\mathrm{p}}$ is the time harmonic index which corresponds to a single value of the spatial harmonic index $k_{\mathrm{p}}$, and $\omega_{0}$ is the fundamental angular frequency. Then, the generic constant $\bar{C}$ can be rewritten as

$$
\bar{C}\left(k_{\mathrm{p}}\right)=\bar{C}^{\theta_{0}}\left(k_{\mathrm{p}}\right) e^{j l_{\mathrm{p}}\left(k_{\mathrm{p}}\right) \omega_{0} t} .
$$

By using the argument of any of the constants contained in $\hat{\bar{A}}_{z}, l_{\mathrm{p}}$ corresponding to each spatial harmonic component can be determined. This is illustrated in Figure 4, where 2 time dependent sinusoidal waveforms $S_{1}$ and $S_{2}$ with corresponding frequencies $\omega_{1}$ and $\omega_{2}$ are shown. Arguments of $S_{1}$ at time instants $t_{1}$ and $t_{2}$ can be expressed, respectively, as

$$
\arg \left(S_{1}\right)\left(t=t_{1}\right)=\omega_{1} t_{1} ; \arg \left(S_{1}\right)\left(t=t_{2}\right)=\omega_{1} t_{2} .
$$

Frequency $\omega_{1}$ can be obtained as

$$
\omega_{1}=\frac{\arg \left(S_{1}\right)\left(t=t_{2}\right)-\arg \left(S_{1}\right)\left(t=t_{1}\right)}{t_{2}-t_{1}} .
$$

Equivalently, $l_{\mathrm{p}}$ in the permanent magnet field model can be obtained as

$$
l_{\mathrm{p}}\left(k_{\mathrm{p}}\right)=\frac{\arg \left(\bar{C}\left(k_{\mathrm{p}}\right)\right)\left(t=t_{2}\right)-\arg \left(\bar{C}\left(k_{\mathrm{p}}\right)\right)\left(t=t_{1}\right)}{\omega_{0}\left(t_{2}-t_{1}\right)} .
$$

Software packages used for the implementation of

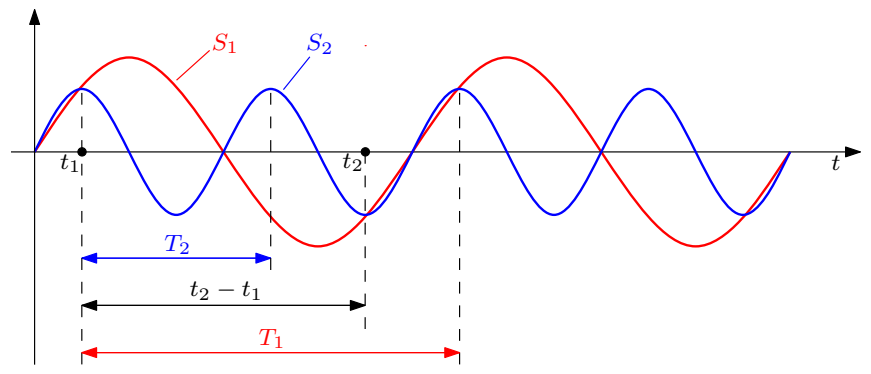

Fig. 4. Determination of arguments of sinusoidal functions varying in time at different frequencies.

the considered model typically give the value of the argument of a complex number in the range between $-\pi$ and $\pi$. Therefore, the numerator of (25) will be between $-2 \pi$ and $2 \pi$, within one period of the time varying waveform. To ensure that (25) gives the correct result, interval $\left(t_{2}-t_{1}\right)$ has to be smaller than the period of the considered time varying sinusoidal waveform, like in the case of waveform $S_{1}$ in Figure 4. If the selected time interval $\left(t_{2}-t_{1}\right)$ is too big for the targeted frequency, (25) does not give a correct result. This would be the case for waveform $S_{2}$ shown in Figure 4, where the chosen time interval $\left(t_{2}-t_{1}\right)$ is bigger than period $T_{2}$. For the benchmark machine, interval $\left(t_{2}-t_{1}\right)$ is chosen to be $1 \mu \mathrm{s}$. If it is assumed that the absolute value of the numerator of (25) is $2 \pi$, time interval of $1 \mu \mathrm{s}$ would be sufficient to accurately determine $l_{\mathrm{p}}$ up to 250 . However, the absolute value of the numerator of (25) for some harmonic components will be lower that $2 \pi$. Therefore, the maximum value of $l_{\mathrm{p}}$ that can be accurately determined is also lower than 250 .

Values of $l_{\mathrm{p}}$ obtained from (25) are shown in Table III for harmonic components listed in Table II. By utilizing $l_{\mathrm{p}}$, (19) can be rewritten as an explicit function of time as

$$
A_{z}\left(r, \theta_{\mathrm{r}}, t\right)=\sum_{k_{\mathrm{p}}=-\infty}^{\infty} \hat{\bar{A}}_{z}^{\theta_{0}}\left(r, k_{\mathrm{p}}\right) e^{j\left(k_{\mathrm{p}} \theta_{\mathrm{r}}+l_{\mathrm{p}}\left(k_{\mathrm{p}}\right) \omega_{0} t\right)}
$$

where $\hat{\bar{A}}_{z}^{\theta_{0}}$ is the solution in the radial direction obtained at the initial rotor position with constants corresponding to the generic constant $\bar{C}^{\theta_{0}}$. As $l_{\mathrm{p}}$ is always a multiple

TABLE III. VALUES OF $l_{\mathrm{P}}$ FOR THE BENCHMARK MACHINE WITH CORRESPONDING VALUES OF $k_{\mathrm{P}}$.

\begin{tabular}{|c|c|c|c|c|c|c|c|c|c|}
\hline$k_{\mathrm{p}}$ & \pm 1 & \pm 5 & \pm 7 & \pm 11 & \pm 13 & \pm 17 & \pm 19 & \pm 23 & \pm 25 \\
\hline$l_{\mathrm{p}}$ & 0 & \pm 6 & \pm 6 & \pm 12 & \pm 12 & \pm 18 & \pm 18 & \pm 24 & \pm 24 \\
\hline
\end{tabular}

of the number of slots, results shown in Table III are in accordance with (18). Combined representation of spatial and time harmonics given by (26) is a very effective way to model time dependency, since each spatial harmonic is merged only with the corresponding time harmonic, without using double summation.

\section{MODEL WITH EDDY CURRENTS IN THE ROTOR}

When eddy currents are considered in the magnet and the retaining sleeve, the governing equation in these regions is given by [2]

$$
\nabla^{2} A_{z}-\mu_{0} \mu_{\mathrm{r}} \sigma \frac{\partial A_{z}}{\partial t}=0
$$

while the governing equation in the air-gap and slots is given by (1). To utilize certain boundary condition 
expressions developed in the magnetostatic model, the solution for the model with eddy currents can first be given for the initial rotor position $\theta_{0}$, and then multiplied by $e^{j l_{\mathrm{p}} \omega_{0} t}$ to include the time dependency, as done in (26). Solutions in the air-gap and slot regions remain the same as given by (4) and (5). Therefore, correlation functions $\chi^{i}$ and $\xi^{i}$ can still be used. The general solution of (27) for the initial rotor position, which holds in the magnet region, is given by

$$
A_{z}^{\mathrm{m} \theta_{0}}\left(r, \theta_{\mathrm{r}}\right)=\sum_{k_{\mathrm{p}}=-\infty}^{\infty} \bar{C}_{\mathrm{m}}^{\theta_{0}} I_{k_{\mathrm{p}}}\left(p_{\mathrm{m}} r\right) e^{j k_{\mathrm{p}} \theta_{\mathrm{r}}} .
$$

The general solution of (27) in the retaining sleeve for the initial rotor position is

$$
A_{z}^{\mathrm{s} \theta_{0}}\left(r, \theta_{\mathrm{r}}\right)=\sum_{k_{\mathrm{p}}=-\infty}^{\infty}\left(\bar{C}_{\mathrm{s}}^{\theta_{0}} I_{k_{\mathrm{p}}}\left(p_{\mathrm{s}} r\right)+\bar{D}_{\mathrm{s}}^{\theta_{0}} K_{k_{\mathrm{p}}}\left(p_{\mathrm{s}} r\right)\right) e^{j k_{\mathrm{p}} \theta_{\mathrm{r}}} .
$$

Terms $\bar{C}_{\mathrm{m}}^{\theta_{0}}, \bar{C}_{\mathrm{s}}^{\theta_{0}}$ and $\bar{D}_{\mathrm{s}}^{\theta_{0}}$ represent unknown complex constants for the initial rotor position, while $I_{k_{\mathrm{p}}}$ and $K_{k_{\mathrm{p}}}$ are modified Bessel functions of the first and second kind or order $k_{\mathrm{p}}$, respectively. Parameters $p_{\mathrm{m}}$ and $p_{\mathrm{s}}$ are introduced as

$$
p_{\mathrm{m}}=\sqrt{j \mu_{0} \mu_{\mathrm{rm}} \sigma_{\mathrm{m}} l_{\mathrm{p}} \omega_{0}}
$$

and

$$
p_{\mathrm{s}}=\sqrt{j \mu_{0} \mu_{\mathrm{rs}} \sigma_{\mathrm{s}} l_{\mathrm{p}} \omega_{0}},
$$

where $\mu_{\mathrm{rm}}, \mu_{\mathrm{rs}}, \sigma_{\mathrm{m}}$ and $\sigma_{\mathrm{s}}$ are introduced in Table I. Expressions (28) and (29), which give the vector potential as a real function, are valid for higher order spatial harmonics, for which holds $k_{\mathrm{p}} \neq \pm 1$. For the fundamental spatial component, for which $k_{\mathrm{p}}= \pm 1$ and $l_{\mathrm{p}}=0$, the vector potential solution in the magnet and in the air-gap is in the form given by (2) and (3), respectively. After applying boundary conditions, by following the same procedure as described in Section II, the unknown constants can be obtained.

The model is implemented by utilizing the reduced set of equations, in a same way as in Section III. The initial position of the rotor is the same one used in the implementation of the magnetostatic model, but the time instant is set to $15 \mu \mathrm{s}$. The validation is again done using 2D finite element model (FEM), and results for the air-gap field are shown in Figures 5 and 6. Again, a good agreement is achieved, with the discrepancy between RMS values of the flux density components corresponding to the HM and FEM being $0.06 \%$ and $0.57 \%$ for the radial and the circumferential component, respectively. However, the model is solved for 0.46

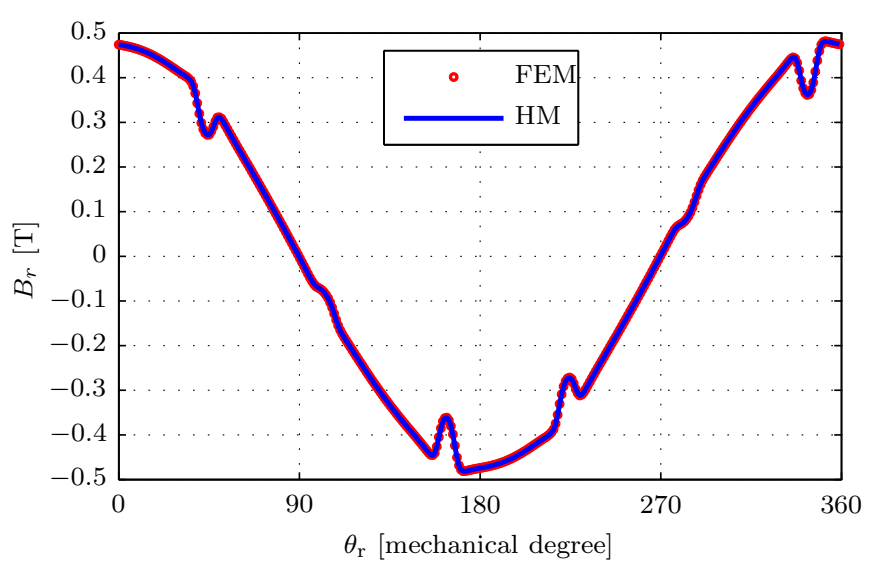

Fig. 5. Radial component of the magnetic flux density in the air-gap, at radius $8.5 \mathrm{~mm}$ and $\mathrm{t}=15 \mu \mathrm{s}$.

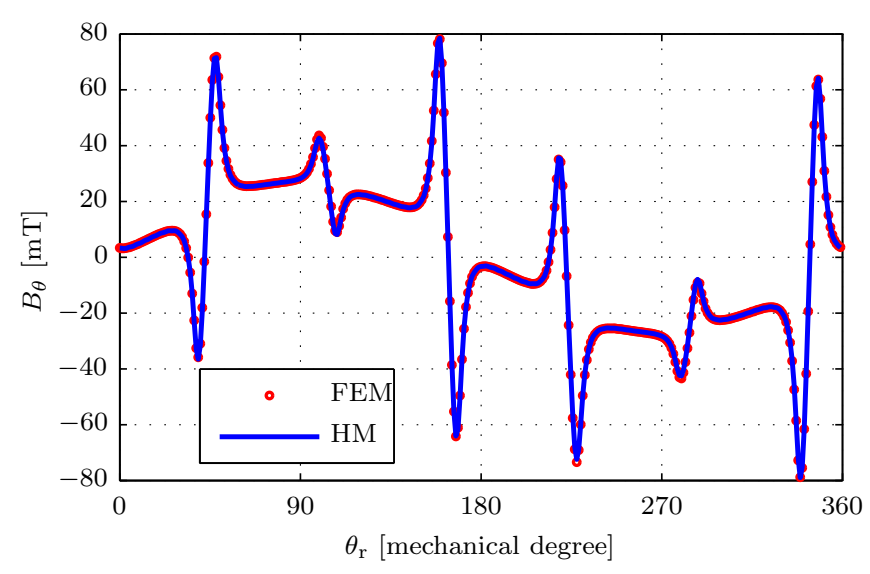

Fig. 6. Circumferential component of the magnetic flux density in the air-gap, at radius $8.5 \mathrm{~mm}$ and $\mathrm{t}=15 \mu \mathrm{s}$.

seconds, which is 3 times longer than the solving time of the corresponding magnetostatic model.

It is difficult to visually distinguish the difference between the displayed results corresponding to the magnetostatic model and the model including eddy currents, and to recognize the effect of eddy currents. For that reason, the distribution of eddy currents in the sleeve at time instant of $15 \mu \mathrm{s}$, obtained by the HM and FEM, is shown in Figure 7. The eddy current density is calculated as

$$
J_{z, \text { eddy }}\left(r, \theta_{\mathrm{r}}, t\right)=-\sigma_{\mathrm{s}} \frac{\partial A_{z}^{\mathrm{s}}\left(r, \theta_{\mathrm{r}}, t\right)}{\partial t},
$$

where $A_{z}^{\mathrm{s}}$ is obtained by using (29) as

$$
A_{z}^{\mathrm{s}}\left(r, \theta_{\mathrm{r}}, t\right)=A_{z}^{\mathrm{s} \theta_{0}}\left(r, \theta_{\mathrm{r}}\right) e^{j l_{\mathrm{p}}\left(k_{\mathrm{p}}\right) \omega_{0} t} .
$$

\section{CONCLUSION}

This paper has demonstrated an effective procedure for modeling the no-load magnetic field in high-speed 


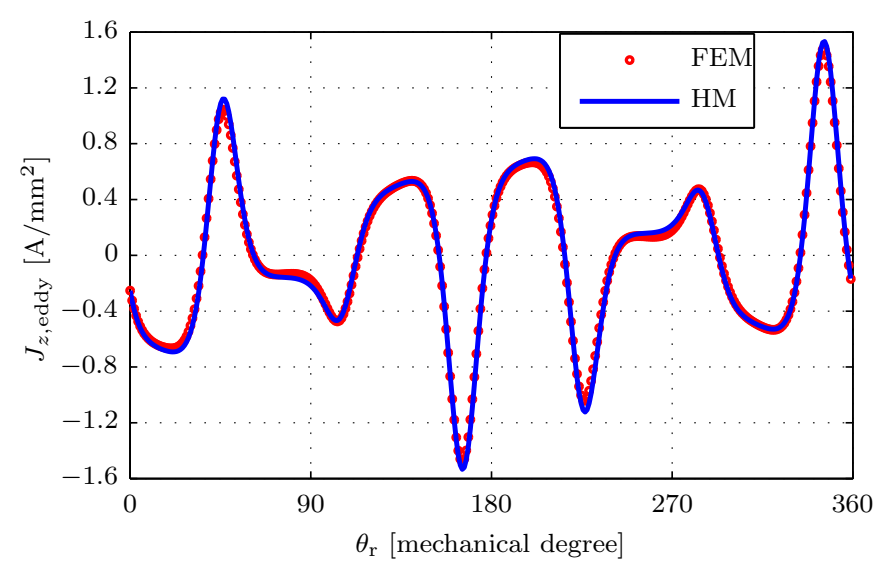

Fig. 7. Eddy current density in the retaining sleeve at radius $7 \mathrm{~mm}$ and $\mathrm{t}=15 \mu \mathrm{s}$.

permanent magnet machines. The model which includes eddy current effects has been built starting from the magnetostatic model. It has been shown that nonexisting harmonic components can be removed from the model in advance, which significantly decreases the size of the model and reduces the solving time. However, the model with included eddy currents requires higher computational time than the corresponding magnetostatic model.

The developed semi-analytical model, which has been successfully validated by the finite element model, is given as an explicit function of time. This allows to further calculate the induced electromotive force. Additionally, using the developed model it is possible to calculate eddy current losses in the rotor due to the slotting effect, as well as to investigate the behaviour of the cogging torque due to the interaction of the permanent magnet and stator teeth.

\section{REFERENCES}

[1] B. L. J. Gysen, "Generalized harmonic modeling technique for 2d electromagnetic problems," Ph.D. dissertation, Eindhoven
University of Technology, 2011.

[2] S. R. Holm, H. Polinder, and J. A. Ferreira, "Analytical modeling of a permanent-magnet synchronous machine in a flywheel," IEEE Transactions on Magnetics, vol. 43, no. 5, pp. 1955-1967, May 2007.

[3] S. Jumayev, "High-speed slotless permanent magnet machines," Ph.D. dissertation, Eindhoven University of Technology, 2017.

[4] M. Merdzan, A. Borisavljevic, and E. A. Lomonova, "Modeling the influence of commutation in voltage source inverters on rotor losses of permanent magnet machines," in 2014 16th European Conference on Power Electronics and Applications, Aug 2014, pp. 1-10.

[5] M. Merdzan, J. J. H. Paulides, and E. A. Lomonova, "Comparative analysis of rotor losses in high-speed permanent magnet machines with different winding configurations considering the influence of the inverter pwm," in 2015 Tenth International Conference on Ecological Vehicles and Renewable Energies (EVER), March 2015, pp. 1-8.

[6] T. Noguchi and M. Kano, "Development of $150000 \mathrm{r} / \mathrm{min}, 1.5$ kw permanent-magnet motor for automotive supercharger," in 2007 7th International Conference on Power Electronics and Drive Systems, Nov 2007, pp. 183-188.

[7] N. Uzhegov, E. Kurvinen, J. Nerg, J. Pyrhnen, J. T. Sopanen, and S. Shirinskii, "Multidisciplinary design process of a 6-slot 2-pole high-speed permanent-magnet synchronous machine," IEEE Transactions on Industrial Electronics, vol. 63, pp. 784795,2016

[8] A. Borisavljevic, "Limits, modeling and design of high-speed permanent magnet machines," Ph.D. dissertation, Delft University of Technology, 2011.

[9] D. C. J. Krop, "Integration of dual electromagnetic energy conversions," Ph.D. dissertation, Eindhoven University of Technology, 2013.

[10] E. P. Furlani, Permanent Magnet and Electromechanical Devices. Academic Press, USA, 2001.

[11] B. Hannon, P. Sergeant, and L. Dupre, "Computational-time reduction of fourier-based analytical models," IEEE Transactions on Energy Conversion, vol. 33, no. 1, pp. 281-289, March 2018. 